J. Clin. Chem. Clin. Biochem.

Vol. 25, 1987, pp. 345-349

(C) 1987 Walter de Gruyter \& Co.

Berlin - New York

\title{
20-Dihydroisomers of Cortisol and Cortisone in Human Urine: Excretion Rates under Different Physiological Conditions
}

\author{
By B. Eisenschmid, P. Heilmann
}

Institute of Clinical Chemistry and Biochemistry, Klinikum Charlottenburg der Freien Universität Berlin, Berlin, F.R.G.

\section{W. Oelkers}

Department of Internal Medicine, Klinikum Steglitz der Freien Universität Berlin, Berlin, F.R.G.

\section{R. Rejaibi and M. Schöneshöfer}

Institute of Clinical Chemistry and Biochemistry, Klinikum Charlottenburg der Freien Universität Berlin, Berlin, F.R.G.

(Received December 22, 1986/February 26, 1987)

Summary: The urinary excretion rates of free cortisol and cortisone as well as of their 20-dihydroisomers have been studied in normal subjects under different physiological or pharmacological conditions. For the estimation of steroid excretion rates, a fully automated, liquid-chromatographic method was used.

In normal subjects, the median steroid excretion rates of free cortisol, cortisone, 20 - $\alpha$-dihydrocortisol, 20- $\beta$ dihydrocortisol, 20 - $\alpha$-dihydrocortisone and 20 - $\beta$-dihydrocortisone were $6.7,8.0,9.8,5.2,5.7$ and $1.3 \mu \mathrm{mol} /$ mol creatinine.

The excretion rates measured at three different intervals of the day followed a circadian rhythm similar to that known for the cortisol secreting activity of the adrenal gland.

After adrenal stimulation by i. v. application of $250 \mu \mathrm{g}$ of tetracosactide hexaacetate, (Synacthen ${ }^{\circledR}$, corticotropin $\left._{\beta 1-24}\right)$ excretion of urinary cortisol was significantly higher than those of the other steroids.

During a $24 \mathrm{~h}$ infusion of corticotropin ${ }_{\beta 1-24}$, the excretion rates of cortisol and its C-20 reduced isomers increased to a significantly greater extent than those of cortisone and its $\mathrm{C}-20$ reduced isomers.

During a four hour infusion of hydrocortisone, the relative increase of cortisol excretion was greater than that of the other șteroids.

During a five-hour infusion of metyrapone at different dosages, the excretion of all steroids decreased in a dose-dependent manner.

The present data indicate that the 20-dihydroisomers of cortisol and cortisone in human urine primarily originate from the peripheral metabolism of cortisol rather than from adrenal secretion. A partial secretion of the C-20-reduced isomers of cortisol by the adrenal gland and an inhibition of 11-oxidoreductase by

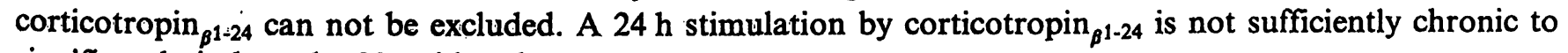
significantly induce the 20-oxidoreductase. 


\section{Introduction}

There is very little published information on the role of the 20-dihydroisomers of cortisol and cortisone in human physiology. In very early publications, only $20 \beta$-dihydrocortisol and 20- $\beta$-dihydrocortisone were described as occurring in human and dog urine (1, 2). Recently, we found that both the $\alpha$ - and $\beta$-isomers of cortisol and cortisone are present in human urine and that the $\alpha$-isomers are predominant $(3,4)$. The origin of these urinary 20-reduced steroids obviously is multilocal. In in vitro experiments, their formation has been shown to occur in rat $(5,6)$, in $\operatorname{dog}(7)$ and in human kidney (8) as well as in the human adrenal cortex (9). The liver may also be involved, although here they are rapidly metabolized to cortols and cortolones (10). In the present experiments, we determined the urinary excretion rates of cortisol and cortisone as well as of their 20-dihydroisomers, 20$\alpha$-dihydrocortisol, 20- $\beta$-dihydrocortisol, 20- $\alpha$-dihydrocortisone, and 20- $\beta$-dihydrocortisone, under different conditions of stimulation and suppression of adrenal steroid secretion. From these in vivo data, we can expect to obtain further information on the origin of these steroids that occur in human urine.

\section{Protocols}

Normal male and female students volunteered for the studies. They consented to participate after the protocols had been carefully explained to them. They had no obvious evidence of metabolic, endocrine, renal, or hepatic disease.

Normal 24 h excretion rates

$24 \mathrm{~h}$ urine samples were collected from 57 normal males and females.

\section{Circadian rhythm}

From four male subjects, urine samples were collected at three different time intervals of the day, from 12.00 to $22.00 \mathrm{~h}$, from 22.00 to $8.00 \mathrm{~h}$ and from 8.00 to $12.00 \mathrm{~h}$.

\section{Short term stimulation by corticotropin}

After collecting fresh urines at $8.00 \mathrm{~h}$, we injected $250 \mu \mathrm{g}$ of tetracosactide hexaacetate (Synacthen ${ }^{\circledR}$, corticotropin $_{\beta 1-24}$ ) into one male and seven female subjects intravenously, and again collected urine specimens $4 \mathrm{~h}$ later.

\section{Long term stimulation by corticotropin}

In three male subjects, urine was collected on a control day from $7.00 \mathrm{~h}$ to $17.00 \mathrm{~h}$. On the second day, starting at $7.00 \mathrm{~h}$ tetracosactide was infused at a rate of $10 \mu \mathrm{g}$ in 24 hours. Urine was collected from $7.00 \mathrm{~h}$ to $17.00 \mathrm{~h}$ and from $17.00 \mathrm{~h}$ to $7.00 \mathrm{~h}$.

\section{Infusion of hydrocortisone}

In five male subjects, $50 \mathrm{mg}$ of hydrocortisone-21-hemisuccinate in $9 \mathrm{~g} / \mathrm{l}$ saline were infused via an anticubital vein from $8.00 \mathrm{~h}$ to $12.00 \mathrm{~h}$. Urine was collected from $10.00 \mathrm{~h}$ to $16.00 \mathrm{~h}$ at two hour intervals.

\section{Suppression by metyrapone $\cdot 1$}

Five male subjects were studied in low-dose and high-dose metyrapone experiments.

In the low-dose experiment, $1 \mathrm{~g}$ metyrapone ditartrate (CibaGeigy, Basle, Switzerland) dissolved in $500 \mathrm{ml}$ of $9 \mathrm{~g} / \mathrm{l}$ saline was infused via an antecubital vein from $8.00 \mathrm{~h}$ to $12.00 \mathrm{~h}$. Urine samples were collected from $8.00 \mathrm{~h}$ to $18.00 \mathrm{~h}$ at two hour intervals.

In the high-dose experiment, $4 \mathrm{~g}$ metyrapone ditartrate were infused under comparable conditions over the $5 \mathrm{~h}$ experimental period. Urine was collected under the same conditions as in the low-dose experiment.

During the high-dose experiment, 2 subjects complained of some burning along the course of the vein infused with metyrapone. No side-effects were experienced in the low-dose experiment.

\section{Methods}

Samples

The urine specimens were stored at $4^{\circ} \mathrm{C}$ during the period of collection, with no preservatives. From the collected urines, aliquots of about $10 \mathrm{ml}$ were stored and frozen until analysis.

\section{Analytical procedure}

Urinary free steroids were estimated by an automated, liquid chromatographic technique, the methodological details of which have been described elsewhere (11). Coefficients of variation range between $8.7 \%$ and $17.0 \%$ for inter-assay variability and between $1.3 \%$ and $5.2 \%$ for intra-assay variability. Assay sensitivity is $15 \mathrm{nmol} / \mathrm{l}$.

\section{Results}

\section{Normal 24 h excretion rates}

Results of excretion rates of urinary steroids are listed in table 1 . The excretion rates are expressed relative to creatinine excretion. A logarithmic distribution of values was assumed. The ratio of 20 - $\alpha$-dihydrocorti$\mathrm{sol} /$ cortisol was 1.5 .

\section{Circadian rhythm}

The relative excretion rates of the urinary steroids at three different time intervals of the day are shown in figure 1 . The changes of the $\mathrm{C}-20$-reduced steroids parallel those of cortisol and cortisone. The ratio of $20-\alpha$-dihydrocortisol/cortisol shown in the upper part of the figure remains constant: 


\section{Stimulation with corticotropin}

After short term stimulation, the relative excretion rates of all the urinary steroids measured increased significantly $(p<0.01)$ (fig. 2$)$. The highest relative increase was found for cortisol, which exhibited a 15.9-fold increase (mean value). The ratio of $20-\alpha-$ dihydrocortisol/cortisol decreased from 2.0 to 0.58 . The changes of the relative excretion rates of steroids during the long term infusion of corticotropin are shown in figure 3. After the control day, excretion rates of cortisol and its C-20-reduced metabolites drastically increased during the first period of infusion and again still further increased during the

Tab. 1. Relative 24-h urinary excretion rates of cortisol and cortisone and their C-20-reduced isomers from normal subjects. Results expressed as lower limit, median and upper limit of measured data.

\begin{tabular}{lllr}
\hline Steroid & \multicolumn{3}{l}{$\begin{array}{l}\text { Steroid } \\
(\mu \mathrm{mol} / \mathrm{mol}\end{array}$} \\
\cline { 2 - 4 } & $\begin{array}{l}\text { Lower } \\
\text { limit }\end{array}$ & Medinine $)$ & \multicolumn{1}{c}{$\begin{array}{l}\text { Upper } \\
\text { limit }\end{array}$} \\
\hline & 6.5 & 9.8 & 14.0 \\
$20 \alpha$-Dihydrocortisol & 2.9 & 5.7 & 11.4 \\
$20 \alpha$-Dihydrocortisone & 2.1 & 5.2 & 8.0 \\
$20 \beta$-Dihydrocortisol & 0.5 & 1.3 & 3.9 \\
$20 \beta$-Dihydrocortisone & 1.8 & 6.7 & 14.0 \\
Cortisol & 4.7 & 8.0 & 13.5 \\
Cortisone & & & \\
\hline
\end{tabular}

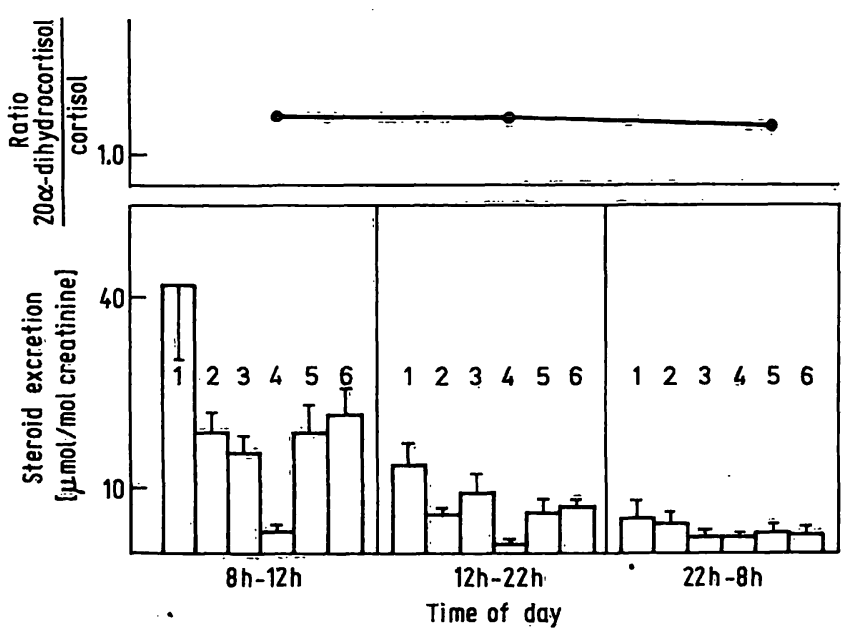

Fig. 1. Relative urinary excretion rates of cortisol and cortisone and their C-20-reduced isomers (mean \pm SEM) at three different time intervals of the day. The ratio of $20-\alpha-$ dihydrocortisol/cortisol in the upper part.

SEM = standard error of mean;

$1=20-\alpha$ dihydrocortisol;

$2=20-\alpha$-dihydrocortisone;

$3=20-\beta$-dihydrocortisol;

$4=20-\beta$-dihydrocortisone;

$5=$ cortisol

$6=$ cortisone. second period of infusion. The ratio of $20-\alpha$ dihydrocortisol/cortisol changed from 2.4 under basal conditions to 0.9 after the second period of corticotropin infusion. Although excretion rates of cortisone and its metabolites also increased during the infusion period of corticotropin, their relative increases were significantly lower than those of cortisol and its metabolites. Thus, the cortisol/cortisone ratio of 0.8 under basal conditions changed to 15.7 after the second period of corticotropin infusion. Data for 20$\beta$-dihydrocortisone were not measurable during the infusion period, since the correspondent peaks were not discernible against the neighbouring high peaks of 20- $\beta$-dihydrocortisol.

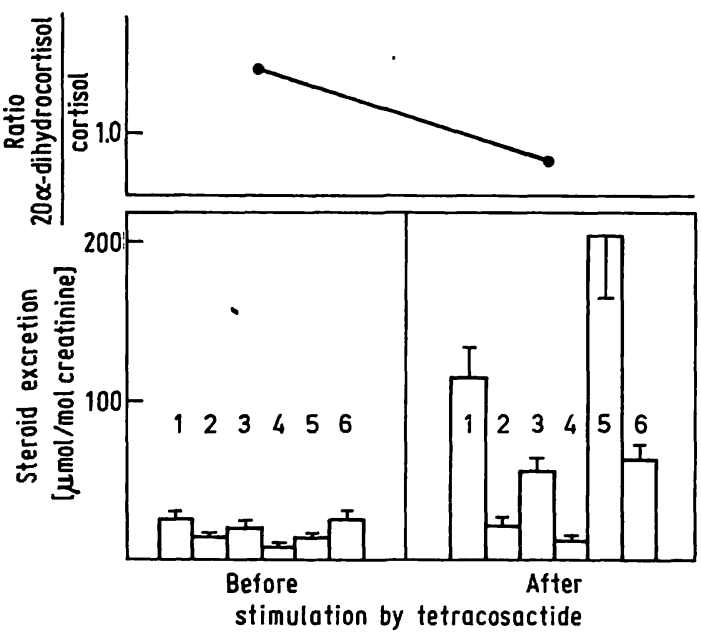

Fig. 2. Relative urinary excretion rates of cortisol and cortisone and their C-20-reduced isomers (mean \pm SEM) before and after adrenal short-term stimulation by tetracosactide (Synacthen ${ }^{\circledR}$ ) in eight normal subjects. Abbreviations are as in fig. 1.

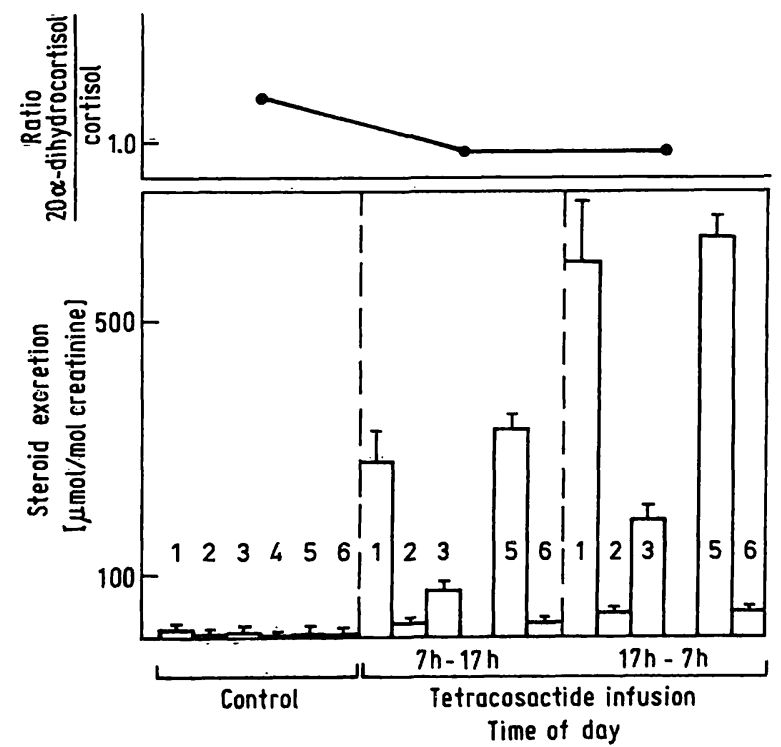

Fig. 3. Relative urinary excretion rates of cortisol and cortisone and their C-20-reduced isomers (mean \pm SEM) before and during a one-day infusion of tetracosactide (Synacthen $\left.{ }^{(}\right)$in three normal subjects. Abbreviations are as in fig. 1. 


\section{Infusion of hydrocortisone}

During hydrocortisone infusion, the excretion rates of all steroids continuously increased up to the end of infusion (fig. 4). Maximum values in the period between 10.00 and $12.00 \mathrm{~h}$ were about $25 \%$ of those found after the second period of corticotropin infusion (fig. 3). After infusion, excretion rates fell towards normal values. The 20 - $\alpha$-dihydrocortisol/ cortisol ratio was lower than 1 during hydrocortisone infusion and higher than 1 after the infusion. The cortisol/cortisone ratio changed from 2.7 during the first two hours of infusion to 1.2 during 14.00 and $16.00 \mathrm{~h}$.

\section{Suppression by metyrapone}

The changes of the relative excretion rates of steroids during low-dose infusion of metyrapone are shown in figure 5. Excretion rates started to decrease during

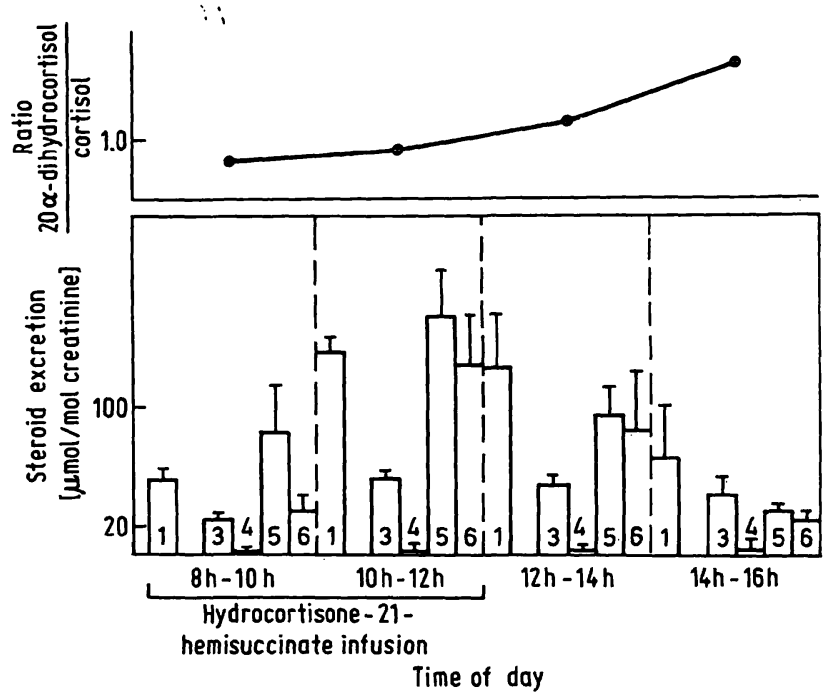

Fig. 4. Relative urinary excretion rates of cortisol and cortisone and their C-20-reduced isomers (mean \pm SEM) during and after a four-hour infusion of hydrocortisone-21hemisuccinate in five normal subjects. Abbreviations are as in fig. 1. the first two hours of infusion. Values were lower than the detection limit from 10.00 to $14.00 \mathrm{~h}$. Excretion rates started to increase up from $16.00 \mathrm{~h}$. In the high dose experiment, the initial fall of excretion rates was steeper and the time of suppression was longer than in the low-dose experiment.

\section{Discussion}

The reference intervals of the excretion rates of the urinary free steroids measured are in accordance with those recently evaluated in the methodological experiments (11).

The excretion rates of the C-20-reduced steroids (fig. 1) follow the circadian rhythm known for the cortisol secreting activity of the adrenal gland (12). As indicated by the constant 20 - $\alpha$-dihydrocortisol/ cortisol ratio, the mechanisms dictating the C-20 reduction of the cortisol and cortisone molecule are not influenced by a circadian rhythm.

Both after adrenal short-term and long-term stimulation by corticotropin (figs. 2 and 3 ), there is a significantly higher increase of urinary cortisol compared with all other steroids. This finding accords with the corresponding data on $6 \beta$-hydroxycortisol (13) and the hypothesis that under conditions of a rapid, exaggerated increase of cortisol in blood, as occurs after corticotropin administration, the binding capacity of transcortin is exceeded and a disproportionately large amount of unbound secreted cortisol appears in the urine. It is striking that the dissociation between cortisol and cortisone, the product of C-11 oxidation, is much more pronounced than that between cortisol and $20-\alpha$-dihydrocortisol, the product of $\mathrm{C}-20$ reduction. This finding may be explained by a higher activity of C-20-oxidoreductase compared with that of the 11-oxidoreductase, or by a significant secretion of

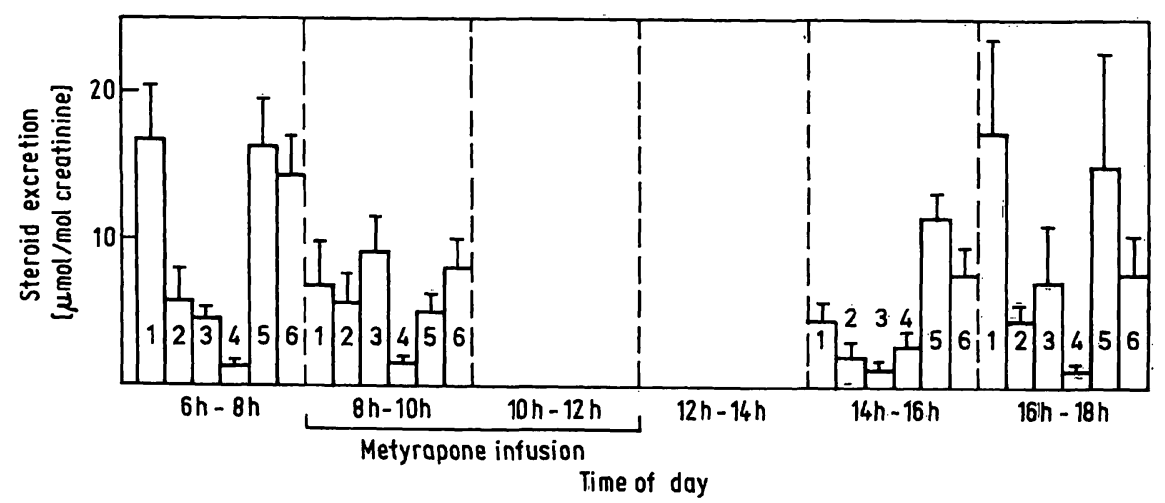

Fig. 5. Relative urinary excretion rates of cortisol and cortisone and their C-20-reduced isomers (mean \pm SEM) during and after a four hour infusion of $200 \mathrm{mg} / \mathrm{h}$ of metyrapone in five normal subjects. Abbreviations are as in fig. 1 . 
20- $\alpha$-dihydrocortisol by the adrenal gland or by an inhibitory effect of corticotropin on 11-oxidoreductase. Under conditions of chronic hypercorticoidism, as occurs in patients with Cushing's syndrome, we found an inverse ratio of cortisol to 20 - $\alpha$-dihydrocortisol, i. e. excretion rates of the $\mathrm{C}-20$ reduced product of cortisol were significantly higher than those of cortisol itself (4). This shift of cortisol metabolism was explained by a trophic effect of cortisol on its own metabolizing enzymes (13). Obviously, the oneday infusion of corticotropin in our experiments is not sufficiently chronic to induce such a metabolic shift.

The findings of the hydrocortisone experiment principally accord with those of the corticotropin experiment, i. e. a pronounced excretion of cortisol compared with that of its metabolites. However, the dissociation between cortisol and cortisone is distinctly lower (cortisol/cortisone ratio of 2.7) if compared with the dissociation observed under the conditions of the one-day infusion of corticotropin (cortisol/ cortisone ratio of 15.9). This finding favours the above mentioned hypothesis that corticotropin may inhibit 11-oxidoreductase.

\section{References}

1. Holness, N. J., Lunnon, J. B. \& Gray, C. H. (1956) J. Endocrinol. 14, 138-145.

2. Gold, N. I. (1961) J. Biol. Chem. 236, 1925-1929.

3. Schöneshöfer, M., Weber, B. \& Nigam, S. (1983) Clin. Chem. 29, 385-389.

4. Schöneshöfer, M., Weber, B., Oelkers, W., Nahoul, K. \& Mantero, F. (1986) Clin. Chem. 32, 808-810.

5. Mahesh, V. B. \& Ulrich, F. (1960) J. Biol. Chem. 235, $356-360$

6. Reach, G., Nakane, H., Nakane, Y., Auzan, C. \& Corvol, P. (1977) Steroids 30, 621-634.

7. Gold, N. I. (1961) J. Biol. Chem. 236, 1930-1933.

8. Jenkins, J. S. (1966) J. Endocrinol. 34, 51-56.

9. Touchstone, J. C., Kasparow, M. \& Blakemore, W. S. (1965) J. Clin. Endocrinol. Metab. 25, 1463-1469.

10. Bradlow, H. L., Fukushima, D. K., Zumoff, B., Hellmann, L. \& Gallagher, T. F. (1962) J, Clin. Endocrinol. Metab. $22,748-753$.
Metyrapone is known to block cortisol biosynthesis by competitive inhibition of adrenal 11-monooxygenase $(14,15)$ and of the "cholesterol-cleavage enzyme" (16). Under the present conditions of metyrapone infusion, plasma cortisol was found to be suppressed within two hours after start of infusion (17). Plasma levels increased again from $15.00 \mathrm{~h}$ in the low dose experiment and from $16.00 \mathrm{~h}$ in the high dose experiment (17). The present findings on steroid excretion rates principally reflect the time course of plasma cortisol. An activating effect of metyrapone on 20 oxidoreductase, as described by Levin et al. (18), could not be confirmed by the present data.

In conclusion, the present data indicate that cortisone and its 20-reduced isomers as well as the 20-reduced isomers of cortisol in human urine primarily originate from peripheral metabolism of cortisol rather than by adrenal secretion. When considering the relatively high excretion rates measured for 20 - $\alpha$-dihydrocortisol under the conditions of a $24 \mathrm{~h}$ infusion of corticotropin (fig. 3), it cannot be excluded that urinary 20 $\alpha$-dihydrocortisol is at least partially due to adrenal secretion, as postulated by Touchstone et al. on the basis of in vitro studies (9).

11. Schöneshöfer, M., Kage, A., Eisenschmid, B., Heilmann, P. Dhar, T. K. \& Weber, B. (1986) J. Chromat. 380, 267-274.

12. Weitzman, E. D., Fukushima, D., Nogeire, C., Roffwarg, H., Gallagher, T. F. \& Hellman, L. (1971) J. Clin. Endocrinol. Metab. 33, 14-23.

13. Voccia, E., Saenger, P., Peterson, R. E., Rauh, W., Gottesdiener, K., Levine, L. S. \& New, M. I. (1979) J. Clin. Endocrinol. Metab. 48, 467-471.

14. Strott, C. A., West, C. D., Nakagawa, K., Kondo, T. \& Tyler, F. H. (1969) J. Clin. Endocrinol. Metab. 29, 6-11.

15. Schöneshöfer, M., Schefzig, B. \& Arabin, S. (1980) J. Clin. Endocrinol. Invest. 3, 229-236.

16. Cheng, S. C., Harding, B. W. \& Carballeira, A. (1974) Endocrinology 94, 1451-1458.

17. Schöneshöfer, M. \& Claus, M. (1985) Acta Endocrinol. $109,378-385$.

18. Levin, J., Zumoff, B. \& Fukushima, D. K. (1978) J. Clin. Endocrinol. Metab. 47, 845-849.

Prof. Dr. Dr. M. Schöneshöfer Institut für Klinische Chemie und Klinische Biochemie Klinikum Charlottenburg der Freien Universität Berlin Spandauer Damm 130 D-1000 Berlin 19 
